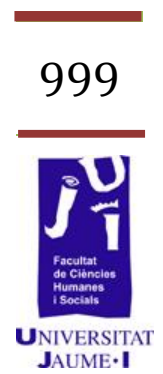

\title{
Art contemporani, per què no?
}

\author{
Marta Almodóvar Fernández \\ al118537@alumail.uji.es \\ María del Mar Castillo Gil \\ maretacastle@gmail.com \\ Andrea Fabregat Fabregat \\ al106894@uji.es
}


I. Resum

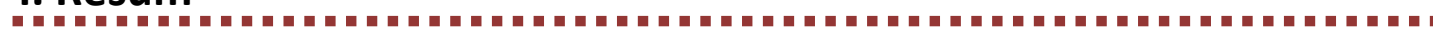

Aquest projecte sorgeix com a conseqüència d'un replantejament de la metodologia emprada en l'educació de les arts visuals en les aules de Primària. Tot i que a l'etapa d'Infantil s'acostuma a treballar l'art d'una forma prou activa, a l'arribar a Primària, molts docents tornen al llibre; en el cas d'aquells que decideixen aventurar-se i abandonar-ho, moltes vegades no saben molt bé com treballar-lo. El que pretenem amb aquest treball és plantejar una línia d'acció pràctica i dinàmica, adaptable a les escoles (que no supose grans modificacions de l'aula ni elevats costos econòmics), que tinga en compte $\mathrm{i}$ aprofite els recursos artístics de la nostra ciutat (museus i galeries) i que, anant més enllà, done cabuda a l'art contemporani, un moviment artístic que tantes possibilitats ens pot oferir. Aquest treball até tant als objectius, la metodologia, les activitats, el procés d'avaluació del projecte com als materials que es necessiten per a la seua implementació i construcció, un protocol per a que els mestres el seguisquen en cas de fer una eixida (en aquest cas a algun espai artístic de Castelló) o les possibles dificultats que pugueren sorgir al llarg del projecte i la forma de solucionar-les.

Paraules clau: Metodologia, educació artística, arts visuals, educació Primària, escoles, espais artístics, art contemporani.

\begin{abstract}
This project arises from a rethinking of the methodology used in the visual arts education during the Primary education period. Although art is worked in an active way during the infant stage, arriving at Primary, many teachers turn to the book. In the case of those who choose to venture and abandon it, often do not know how to work it. The aim with this work is to propose a practical and dynamic course of action, adaptable to schools (which does not involve big changes in the classroom or high economic costs), which takes into account and uses the artistic resources of our city (museums and galleries) and, beyond that, to introduce the contemporary art, an artistic movement which can offer us so many possibilities. This project attends to objectives, methodology, activities and the evaluation process but at the same time, it also includes the materials which are necessary for his implementation and construction, a teachers' protocol to be followed if they decide to hike with their pupils (in our case to an art space in Castellón) or the possible difficulties that may arise during the project and how to solve them.
\end{abstract}

Key words: Methodology, artistic education, visual arts, Primary education, schools, art spaces, contemporary art. 
Art contemporani, per què no? Aquest és el títol del nostre projecte $\mathrm{i}$ precisament va ser la pregunta que ens vam realitzar quan vam començar a analitzar la situació de l'educació i concretament de l'educació artística a les nostres escoles.

Però què és això de l'educació artística? Definir-la és complicat si no comprenem les dos paraules que integren aquest concepte: educació i art. La educació ha tingut sempre una enorme transcendència ja que de ella depèn el nostre desenvolupament com a persones. D'acord amb Fontal, l'educació pot definir-se com:

procesos y experiencias de (re)socialización (recognición y reinvención), orientados a aumentar y consolidar capacidades individuales y colectivas de los sujetos populares mediante la recuperación y recreación de valores, la producción, apropiación y aplicación de conocimientos que permitan el desarrollo de propuestas movilizadoras (Souza, 2005: 94).

En el nostre cas, ens estem referint a una educació en el camp de l'art, entenent-lo com «algo que nos rodea y que no nos detenemos a considerar, está presente en todo lo que agrada a nuestros sentidos, e invita a la reflexión. La obra de arte no necesita más que de tres requisitos para que se realice, un ser sensible que necesite expresar algo, un lenguaje claro y un espectador predispuesto a captar ese mensaje» (Marco, 2006: 147).

En aquest sentit, podem establir una relació amb les paraules de Gardner (1994: ) al afirmar que: "las artes proporcionan un marco especial, puede que incluso único, de expresión personal». Per tant, l'art és interpretat com una forma d'expressió i comunicació. Però a més, l'art és beneficiós en molts altres sentits; facilita el desenvolupament socioemocional del xiquet ja que propicia l'acceptació de si mateix amb les seues possibilitats i els seus límits; li permet construir el seu patrimoni personal (o identitat) artístic i cultural i finalment, li ajuda a establir vincles amb l'ambient que li envolta. Si fusionem aquestos dos conceptes, ens trobem amb l'educació artística. Aquesta, tot i que es tracta d'una àrea educativa molt més específica, per la seua naturalesa també continua tenint una gran amplitud de camp. Per tant, parlar d'educació artística a les aules ha de suposar un plantejament didàctic obert i extens, que permeta tant la producció i expressió artística dels nostres alumnes com l'apreciació i valoració d'aquelles obres ja existents.

Totes aquestes consideracions ens fan allunyar-nos d'una altra concepció de l'art que desgraciadament també s'ha estat propagant als nostres dies:

En cuanto al término arte que se maneja [...] deriva, por supuesto, del concepto que en nuestra sociedad se tiene del arte y del artista, anclados ambos en los paradigmas modernistas, o incluso románticos, en esa idea mitificada que nos 
transmiten los medios e instituciones [...] donde el creador de productos visuales es un hombre blanco, excéntrico y sucio, que trabaja sin orden y sin objetivos, pero que, dotado de una capacidad sobrenatural, produce objetos asombrosos. Debido a esta particular forma de crear, permanece en la sociedad la idea de que no se puede enseñar a hacer arte, por lo que cuando se trabaja con la infancia, la educación artística queda reducida a la enseñanza de unas cuantas técnicas cuanto más vistosas mejor (Acaso, 2006: 230)

Si atenem a la LOE o Llei Orgànica d'Educació (2006) vigent en aquest moment, podem comprovar que dins l'art. 17. "Objetivos de la educación primaria" apareix el següent objectiu: j) Utilitzar diferents representacions i expressions artístiques i iniciar-se en la construcció de propostes visuals. Aprofundint més en el tema i anant al BOE n. 293 (2006), on es fan explícites les ensenyances mínimes per a aquesta etapa, trobem que a l'apartat de competències bàsiques, es considera que una d'elles ha de ser la Competència artística i cultural. Què implica aquesta competència? Al parlar de competència, ens referim al conjunt d'habilitats i destreses que al llarg d'aquesta etapa l'alumnat haurà d'anar assolint per tal de constituir-se com a persona. Per tant, la competència artística i cultural ha d'englobar aquelles habilitats relacionades amb l'apreciació i valoració de manifestacions artístiques i culturals i al mateix temps, el coneixement i utilització d'algunes de les tècniques i recursos artístics que es s'han anat emprant al llarg del temps. Però a banda d'aquestos dos aspectes que ja abans havíem comentat, la competència a la que fem referència, també té present uns altres elements que considerem peces clau per al bon funcionament de l'educació artística (i en realitat de qualsevol altre tipus d'educació): I'ús del pensament divergent i convergent, fet que implica el replantejament i reelaboració d'idees ja existents i l'obertura a noves formes de pensar; l'entrada en funcionament de la iniciativa, la creativitat i la imaginació a l'hora d'expressar-nos i el treball col-laboratiu amb la resta de la comunitat educativa per tal d'ampliar fronteres i aprendre a respectar les manifestacions dels altres.

L'educació artística, que seria considerada com una àrea de coneixement dins de l'educació primària, s'encarregaria principalment de l'assoliment de la competència artística i cultural ja que estan directament relacionades. Però també, s'encarregaria de la consecució d'altres competències com puguen ser la competència en el coneixement $\mathrm{i}$ interacció amb el món físic, la competència per a aprendre a aprendre o l'autonomia i iniciativa personal (BOE, 2006). Ara bé, la metodologia emprada a l'educació primària és l'adient per tal d'aconseguir aquestes i altres competències? Aquest projecte sorgeix a partir de la idea de que, actualment, les pràctiques educatives que s'estan portant a terme en aquest àrea no ho són. Després de passar per l'etapa Infantil, on en la majoria d'escoles s'ensenya a partir de projectes, aquestos queden abandonats $i$ en el seu lloc apareixen els llibres. Llibres que recullen els continguts pertanyents a cada una de les àrees de coneixement. Aquesta 
pràctica pot classificar-se com tancada i inflexible, ja que dona poc marge a un altre tipus d'accions. A més, l'ús dels llibres quedaria lluny de la consecució de les competències abans esmentades ja que la iniciativa, la imaginació, la creativitat o el pensament divergent difícilment es poden desenvolupar quan ja t'ho donen tot programat. El que ací pretenem és la reformulació del nostre treball dins de l'àrea de l'educació artística en base als projectes educatius que es porten duent a terme a l'etapa Infantil. Per tant, el que defensem és la implementació d'aquestos projectes en Primària, com a via per a treballar les arts visuals.

Aquesta proposta, al mateix temps implica anar més enllà de l'aula, descobrint de forma real l'entorn artístic que ens envolta. Això implica l'atenció als espais artístics de la nostra ciutat.

El escenario del conocimiento se traslada, sale del aula, considerando al Museo o espacio expositivo -la gran escuela- el centro didáctico por excelencia [...] El Mueso es una fuente de recursos que contiene una ciudad o sociedad en general que ha de tenerse en cuenta, pues allí se guardan las obras más significativas que son testimonio de una época y de un pensamiento, y más cuando es contemporáneo, de nuestra propia vida. El Museo es recurso, no de una actividad puntual de un solo día, sino es una base para una programación de actividades, lecturas y propuestas, y ésta puede ser de una sola disciplina así como interdisciplinar (Marco, 2006:148-149)

En el nostre cas, el projecte es centra en I'EACC (Espai d'Art Contemporani de Castelló) perquè precisament és en l'art contemporani on nosaltres trobem la nostra ferramenta de treball. L'art contemporani, com el seu propi nom indica, és un moviment artístic que sorgeix al món contemporani, al món actual, als nostres dies. Per tant, quan parlem d'art contemporani, no podem eludir el terme postmodernitat 0 art postmodern, ja que aquest, seria posterior al moviment artístic anterior: el modernisme.

La preferència per aquest moviment i no altre es deu a que «el contexto de la postmodernidad nos ha enseñado que la diversidad es posible $y$, con ella, la convivencia afable de todos los tiempos y opciones; ya no es necesaria la exclusión. La complejidad forma parte de nuestras estructuras» (Colom, 1997: 7)

Si bé hem volgut explicar la nostra decisió pel que fa a l'elecció aquest moviment artístic i no altre, som conscients i de fet esperem que aquesta metodologia de treball no quede relegada a l'art contemporani. La nostra proposta s'ha dissenyat amb la idea de poder ser adaptada a altres espais artístics i a altres moviments artístics. Aquesta idea és fonamental si volem aconseguir un canvi total i no parcial pel que fa a la forma de treballar en aquesta assignatura.

Abans de continuar, hem considerat necessari fer referència a un altre projecte que des de la UJI, s'ha portat a terme pel que fa a l'educació i l'art contemporani. "Imatge i moviment a través de l'art contemporani en 
Educació Infantil» (Almodóvar et al., 2012), és molt important per a nosaltres ja que guarda una gran relació amb el tema que ens envolta (l'art i l'educació). De fet, alguns dels seus autors, són al mateix temps autors d'aquesta publicació. Ara bé, la diferència amb allò que ara presentem és que a l'altre projecte, el punt de mira està ficat en I'Educació Infantil (no en l'Ed. Primària) i allò que es vol reflectir són les experiències reals que mitjançant el treball conjunt entre una escola de Castelló de la Plana, l'alumnat i professorat de la UJi que es va implicar i un dels espais artístics de la ciutat (EACC) es van poder viure (la publicació que ara ens ocupa està més centrada en el canvi de metodologia pel que fa a l'educació artística i no tant en les experiències).

A continuació, es presenten aquells objectius a partir dels quals va sorgir i es va desenvolupar el nostre mètode i la nostra metodologia de treball. Finalment, tractarem d'establir una sèrie de resultats i les conclusions que es deriven de tots aquestos punts.

\section{Objectius}

La principal finalitat que ens hem plantejat a l'hora de realitzar aquest treball és la d'utilitzar una nova metodologia en Educació Primària, per a treballar les arts plàstiques, on en lloc de treballar mitjançant un llibre, treballarem a partir de projectes de treball sobre l'art contemporani. Però a més, amb els subjectes amb qui es pretén dur a terme aquest projecte (alumnat de Primària), ens plantegem una sèrie d'objectius més específics l'assoliment dels quals els permetrà:

1. Conèixer i dominar materials, ferramentes, suports... diferents als que estan acostumats a utilitzar.

2. Passar les fronteres de l'aula i arribar als espais d'art de la ciutat.

3. Desenvolupar la creativitat.

4. Observar i explorar l'entorn més pròxim amb la intenció de Utilitzar el llenguatge plàstic com una forma d'expressió i comunicació d'emocions i sentiments.

A més considerem molt important fer una petita menció a la importància que té treballar per projectes educatius en educació i als seus objectius, motiu pel qual defensem treballar amb aquesta metodologia. Alguns d'aquestos objectius són:

- Aprendre a aprendre.

- Aprendre a investigar.

- Dur a terme com a docents la inclusió educativa i social.

- Conèixer i aprendre els valors d'igualtat i de cooperació en el treball. 
Aquests objectius són, entre molts altres, els que ens han portat a triar aquesta metodologia, més característica d'educació infantil que d'educació primària, però que té molt bons resultats i que ajuden als nens a accedir a coneixements d'una manera diferent.

La creativitat és una de les ferramentes més útils per a l'adaptació a la realitat complexa i canviant que ens toca viure i per això considerem de gran importància el bon ensenyament de les arts visuals a l'escola.

\section{Material i mètode}

Per a dur a terme el nostre projecte, en primer lloc, era necessari analitzar la situació actual de l'assignatura de plàstica en les aules del primer cicle de primària. El nostre treball, llavors, es fonamentaria sobre la situació real i donaria resposta a les mancances d'aquesta.

El instrument de mesura utilitzat per a la recollida d'aquesta informació va ser un qüestionari elaborat per nosaltres mateixes. El qüestionari, constava de 20 ítems a contestar entre una escala de valoració de l' 1 al 5 (1: Inadequat, 2: En ocasions, 3: Acceptable, 4: Adequat i 5: Molt adequat). Les preguntes tracten del seu coneixement sobre els diferents museus, localitzacions, exposicions, així com dels propis interessos i els seus coneixements sobre la matèria (ANNEX 3).

La població escollida per a la realització del test va ser els i les mestres de primer cicle d'Educació Primària del CEIP Bernat Artola, ubicat en la ciutat de Castelló de la Plana. El nombre total de persones van ser 4.

L'anàlisi dels resultats ens va permetre detectar les carències que hi havia a l'hora d'ensenyar l'àrea de plàstica en l'etapa; a partir d'aquestes, es va desenvolupar tot el nostre projecte.

Aquest aposta per una perspectiva globalitzadora que parteix de les activitats que el conformen per a fer referència a les diferents competències bàsiques que vénen donades a la LOE. A més, si sorgeix l'oportunitat de treballar continguts d'unes altres àrees, aprofitarem la situació i la matèria de plàstica per a fer-ho. També hem tingut en compte els principis pedagògics que marca la LOE en l'article 14, com poden ser: partir dels coneixements previs del xiquet, l'aprenentatge significatiu o el principi de globalització.

L'aprenentatge significatiu, com marca la LOE, és un punt clau del nostre treball ja que plantegem situacions que provoquen en el xiquet un conflicte cognitiu a través d'activitats atractives significatives, partint de les necessitats dels alumnes. D'acord amb açò, les activitats plantejades són lúdiques, motivadores i actives, on el xiquet participa i és el protagonista del seu aprenentatge (ANNEX 1 i 2). Treballarem individualment, per parelles, en petit grup i en gran grup i realitzarem 
algunes activitats d'intercicle. Amb aquestes fomentarem la socialització, el treball cooperatiu i actituds de tolerància i respecte. A més, utilitzem una dinàmica o tècnica especial: "La tècnica del padrí". Aquesta tècnica es caracteritza per l'ajuda i recolzament entre alumnes, ja sigui dins del mateix grup-classe o entre diferents nivells.

La metodologia en l'aula es caracteritza per ser constructivista, globalitzadora, socialitzadora, motivadora, activa, participativa i creativa. A més, la hem anomenat "MAJICA", perquè és una Metodologia (M) Activa (A), basada en el Joc $(J)$, a partir del qual el nostres alumnes Interioritzen (I) els Coneixements (C) i els Apliquen (A).

Per finalitzar el present punt, apuntar que la metodologia que emprem és eclèctica, és a dir, es nodreix dels avantatges de les diferents tècniques, models, principis i corrents, evitant així possibles limitacions a l' aula i amb els nostres alumnes. Així, ens situem i utilitzem uns mètodes o altres depenent del moment concret del procés d' ensenyament- aprenentatge. Tot aquest plantejament no haguera sigut possible sense la construcció $i$ recerca dels materials corresponents. Quant a aquestos, podem dir que són molt diversos: des del qüestionari d'autoavaluació del qual parlàvem abans fins a les fitxes, autoritzacions i notes que al llarg del projecte hem anat creant. La majoria d'ells, han sigut elaborats per nosaltres (les mestres): qüestionaris d'avaluació per a l'alumnat, mestres i famílies, protocol d'actuació per a establir contacte amb els espais d'art de la ciutat (ANNEX 4), fitxes del projecte... No obstant, en altres ocasions, serien els alumnes els autors dels materials com les notes informatives als pares o les obres creades a les activitats plantejades.

\section{Resultats}

Dins d'aquest apartat, en primer lloc hem de dir que no ha sigut possible dur a terme el projecte d'innovació educativa. Tot i que el grup sencer de treball que hem estat treballant teníem ganes i volíem fer l'esforç, una sèrie de causes externes al projecte ha impossibilitat la seua posada en marxa. Per tant, no podem donar uns resultats segurs i basats en la nostra realitat. Encara així, hem investigat escoles en les que si que es duen a terme projectes d'investigació en arts plàstiques basats en projectes educatius d'art contemporani i on els quals, han tingut èxit.

Treballar amb projectes en Educació Primària suposa ser conscients, com a docents que som, de la importància que té que els nens siguen el protagonistes del seu aprenentatge, que investiguen, que ens diguen quins són els seus interessos i coneixements; açò fa que estiguen més motivats i que aprenguen de una manera natural. 
Per a realitzar aquest projecte d'innovació educativa, com hem esmentat abans, hem buscat informació sobre altres escoles on hagen dut a terme aquest tipus de projectes siga en educació infantil, primària, secundària o amb grups d'adults, ja que el que ens interessava era conèixer si aquest tipus de treball funcionava.

Un dels casos que hem analitzat és El Cas de "Fundaçao de Serrevales» (Garcia i Guillen, 2011), on els resultats en el grup de menors de 18 anys van ser els que ens van animar a proposar el projecte a una escola d'educació primària.

Els docents es mostraven molt participatius amb el programa. D'alguna manera la seva participació en l'elecció del tema i de la forma és un punt de partida positiu per a la seva implicació. La majoria es preocupa de que el grup responga a les seves expectatives com a bon grup.

També ens hem fixat en el replantejament del museus d'art fa una dècada i al moment actual; molts d'aquestos s'han remodelat per a poder realitzar projectes educatius. Per a obtindre aquesta informació hem llegit un article d'investigació de Fontal (2009) on ens parla dels museus com espais per a l' aprenentatge on és possible explorar, analitzar, debatre, negociar, construir; fer-nos persona, fer món. Adonar-nos de la possibilitat de transformar la realitat. Per això és molt important que el museu estiga implicat en aquestos projectes, perquè d'això depèn que funcione o no un projecte com el que proposem.

Per últim, hem analitzat també el projecte "El arte de cada día» (Bondía, 2010), projecte educatiu per a l'escola dels nostres dies. En aquest projecte s'impliquen tant els artistes, el centre educatiu com el museu. Quan el projecte va concloure, tots les persones implicades van mostrar la seua satisfacció amb el projecte. D'una banda, els artistes el van considerar molt interessant ja que no havien viscut una experiència artística amb alumnat tan menut; d'altra banda, el professorat va confirmar que el contacte amb els artistes, els va donar una visió molt més humana de l'art, la qual els ajuda a comprendre'l millor i a respectarlo d'un mode distint.

Finalment, els alumnes van mostrar molt de interès en una assignatura que fins al moment havia estat tan poc reconeguda per ells. Generalment l'opinió de l'alumnat és que allò que més els agrada són les exposicions en les que ve l'home/dona que ha pintat aquestos quadres i els explica com ho ha fet. Els agrada moltíssim aprendre noves tècniques i senten que sempre són sorpresos per alguna cosa nova de manera que volen continuar participant en projectes similars.

L'avaluació d'aquest projecte va ser molt positiva, a la vista dels treballs dels alumnes i les actituds cap a aquestos tallers basades en el interès que genera el coneixement dels artistes i la creativitat de les propostes. S'han 
exposat sis-cents treballs al trimestre, el que ha suposat un important esforç del col-legi i dels 7 professors que imparteixen l'assignatura d'Educació Plàstica en primària. Tots ells han mostrat en tot moment la seva il-lusió pel projecte i han intentat aprendre el particular enfocament que requereix aquesta assignatura.

Un projecte com aquest deu integrar-se en el currículum de l'assignatura. Una tasca pendent de gran importància per a que no supose un extra en la ocupada vida dels estudiants. És imprescindible que els tallers es realitzen dins i fora de classe i disposen del temps suficient per a la seva realització. Aquestos tallers connecten directament i d'una forma més eficient amb alguns alumnes dels conceptes que l'alumne deu d'aprendre en el seu pas per l'escola.

Fins ací, hem presentat l'anàlisi de resultats d'alguns dels projectes que hem investigat per a confirmar que el nostre projecte, en cas de dur-lo a la pràctica, podria tenir èxit.

\section{Discussió i conclusions}

Plantejar un projecte com aquest sense haver pogut dur-lo a la pràctica ens dificulta la tasca a l'hora de poder d'establir unes conclusions en referència a l'èxit o fracàs del nostre projecte. En canvi, si que podem afegir una sèrie de reflexions pel que fa a la construcció i desenvolupament d'aquest projecte. Així, si atenem als objectius plantejats, pensem que no són utòpics sinó més bé assolibles amb una mica d'esforç i dedicació ja que principalment, ens basem en un canvi de metodologia que permeta resoldre i millorar els resultats obtinguts en el camp de l'educació artística. En relació amb aquest objectiu, hem desenvolupat una metodologia on des d'un primer moment, allò que ha primat ha sigut l'accessibilitat des de tots els sectors educatius, és a dir, la possibilitat de dur-lo a la pràctica siga quin siga l'escola i les característiques d'aquesta. De fet, tot i que el projecte s'ha pensat per a localitats on es dispose d'espais artístics, aquesta part del projecte es podria modificar i fer un acostament a aquestos recursos mitjançant llibres, revistes, internet... Afortunadament, les noves tecnologies també avancen en aquest sentit i museus tan interessants com el TATE de Londres, han desenvolupat un sistema informàtic a la xarxa que permet visualitzar el interior del museu des de qualsevol racó del món. Això, ens permet no només treballar en un àmbit local sinó també en un nacional $\mathrm{i}$ inclús internacional.

Tot i així, aquesta metodologia no es pot posar en pràctica sense la presència del personal docent corresponent. Aquest serà el guia del projecte, oferint diferents possibilitats o camins als seus alumnes. Ara bé, no determinarà el camí a seguir sinó que seran els alumnes qui, 
mitjançant la investigació i la seua pròpia experiència, hauran de decidir quin serà el que volen triar.

La figura del mestre, a més de servir de guia dels seus alumnes, servirà de guia del seu propi aprenentatge ja que partim d'un concepte d'educació on tots ensenyen $\mathrm{i}$ aprenen dels altres.

Pel que fa als resultats, com s'ha pogut observar, no els hem pogut contrastar però els resultats observats en aquelles escoles en que s'han dut a terme projectes semblants, ens permeten afirmar que aquesta forma de treball pot tenir èxit i pot ajudar a ampliar i millorar el bagatge artístic dels nostres alumnes.

Per tant, i d'acord amb allò exposat, deixem oberta la nostra pregunta i la acompanyem amb altres noves:

Art contemporani, per què no? Art modern, per què no? Art barroc, per què no? Educació artística fora de l'aula, per què no? Educació artística per projectes dins l'etapa Primària, per què no?

Aquestes preguntes no persegueixen altre objectiu que fer-nos reflexionar sobre la necessitat de qüestionar constantment la nostra pràctica docent; ara bé, un reqüestionament plantejat en forma de crítica constructiva al nostre treball. Aquesta, serà la millor forma d'adonar-nos del que estem fent a l'aula, quines coses estan funcionant, quines es podrien millorar i quines altres s'haurien de canviar. En definitiva, millorar com a mestres i millorar com a persones.

La educación artística no pretende tanto que la persona aprenda a hacer arte como que, a través del arte, se aprenda a ser persona (Marín Viadel, 1991: 116-119)

\section{Bibliografia}

ACASO, M. (2005): «Repensando el arte infantil: una propuesta para la práctica», en BELVER, M. H. i altres (eds.) (2005: 227-235).

ALMODÓVAR, M. i altres (eds.) (2012): "Imatge i moviment a través de l'art contemporani en Educació Infantil», publicacions de la UJI, Castelló de la Plana.

ANGULO, J.L. i N. BLANCO,(1994): Teoría y desarrollo del Currílucum, Aljibe, Málaga

BADIA, M. i altres (eds.) (2003): Figuras, formas y colores: propuestas para trabajar la educación plàstica, Graó, Barcelona.

BELVER, M. H. i altres (eds.) (2005): Arte infantil en contextos contemporáneos, Eneida, Madrid. 
BERROCAL, M. i altres (eds.)(2005): Menús de educación visual y plàstica, Graó, Barcelona.

BONDÍA, A. (2010): «El arte de cada día: proyecto educativo para la escuela de hoy». Pulso, no33. p. 161-187.

COLOM, A. J. (1997): "Postmodernidad y educación: Fundamentos y perspectivas», Educació i Cultura. Revista Mallorquina de Pedagogia, 1, 10, Universitat de les Illes Balears, Palma.

CONTRERAS, J. (1994): Enseñanza, currículum y profesorado, Akal, Madrid.

DORAN, E. i altres (eds.)(2006): Colour, Tate, London.

DORAN, E. (2005): $A$ is for artist, Tate, London.

EFLAND, A. D. (2004): Arte y cognición. La integración de las artes visuales en el currículum, Octoedro, Barcelona.

EISNER, E. W. (2004): El arte y la creación de la mente, Paidós Ibérica.

EISNER, E. W. (1987): Procesos cognitivos y currículum, Martínez Roca, Barcelona.

EISNER, E.W. (2004): El arte y la creación de la mente, Paidós, Barcelona.

FIGUERAS, M. (2000): Traçtocats, experiències plàstiques amb l'art, Ventall, Barcelona.

GARCIA, A. i F. GUILLEN (2011): "Innovación educativa y compromisos expositivos en los museos de Arte Contemporàneo». Publicacions de la Universidad de Murcia, Murcia.

GARDNER, H. (1994): Educación artística y desarrollo humano, Paidós, Buenos Aires.

GARDNER, H. (1999): Inteligencias múltiples. La teoría en la práctica, Paidós, Barcelona.

GIMENO SACRISTÁN, J. i A. I. PÉREZ (1992): Comprender y transformar la enseñanza, Morata, Madrid.

GOODMAN, D. I Z. MILLER (2009): Shape, Tate, London.

HERNANDEZ, F. i altres (eds.) (1991): ¿Qué es la educación artística?, Sendai, Barcelona.

IVAM (1998): Los talleres didácticos del IVAM. Propuestas didácticas en torno a 7 talleres (N. Gabo, R. Hausmann, A. Warhol, K. Schwitters, F. Picabia, D.Smith, E.Satie), IVAM, Valencia. 
IVAM (2004): Los talleres didácticos del IVAM, 1998-2005. Propuestas de actividades didácticas del Museo en torno a artistas modernos (Klee, Chillida, Liechtenstein...) y contemporáneos ( $P$, Taaffe, H. Voth...), IVAM, Valencia.

LLONA, M. (2012): «El arte contemporàneo como recurso educativo en Educación Primaria». Publicacions de la Universitat Internacional de La Rioja. Facultad de Educación, la Rioja.

LÓPEZ-BOSCH, M. (2006): El lenguaje visual, Paidos, Barcelona.

LÓPEZ-BOSCH, M. (2009): La Educación artística no son manualidades: nuevas prácticas en la enseñanza de las artes y la cultura visual, Paidos, Barcelona.

LOWENFELD, V. i W. LAMBERT (1977): Desarrollo de la capacidad creadora, Kapelusz, Buenos Aires.

LUPTON, E. i J. LUPTON (2007): D.I.Y. Kids, Princeton Architectural Press, New York.

MARCO, P. (2006): «El niño ante el arte», en JUNTA DE CASTILLA Y LEÓN (ed.): Arte contemporáneo y educación: un diálogo abierto, Publicacions de la Junta de Castilla y León, Espanya.

MARTÍNEZ, M.L. i altres (eds.)(2008): Nuevas propuestas de acción en educación artística, Servicio de publicaciones e intercambio científico de la Universidad de Málaga, Málaga.

POZUELOS, F.J. i A. ROMERO (2002): Decidir sobre el curriculum. Distribución de competencias y responsabilidades, M.C.E.P.

RAIMONDO, J. (2004): Art for explorers, Watson-Guptill.

RODRIGUES DA COSTA, F. J. (2005): «Didáctica, acción educativa y arte infantil» en BELVER, M. H. i altres (eds.) (2005: 37-47).

STIEFF, B. (2011): Hundertwasser for kids, Prestel, London.

TORRES M. i R. JUANOLA (1998): Una manera d'ensenyar arts plàstiques a l'escola. 140 exercicis per a educació infantil i primària, Associació de mestres Rosa Sensat, Barcelona

TORRES M. i R. JUANOLA (2011): Dibuixar, mirar i pensar. Consideracions sobre educació artística, Associació de mestres Rosa Sensat, Barcelona.

WATT, F. (2005): The Usborne Book of Art projects, Edc Pub, England.

WOODFORD, S. (2002): Cómo mirar un cuadro, Gustavo Gili, Barcelona.

ZABALZA, M.A. (1991): Diseño y desarrollo curricular, cap. II, 4a Edició, Narcea S.A., Madrid. 
Annexos

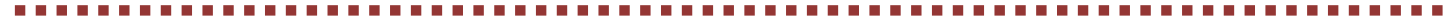

Annex 1: EXEMPLE 1. ACTIVITATS DEL PROJECTE

Títol activitat

\begin{tabular}{|l|l|l|l|l|l|}
2 & \\
\hline
\end{tabular}

\begin{tabular}{|l|}
\hline Duració \\
\hline Materials \\
\hline
\end{tabular}

Desenvolupament

de

l'activitat

2 hores

Diferents tipus de paper, cartró, colors, pintures, retoladors, tisores, pegament... Tot tipus de material que ens puga servir per a treballar diferents tècniques.
TREBALLEM LA TÈCNICA DE L'AUTOR - PART 1

L'aula normal
Observacions
Per a començar, la mestra els mostrarà diferents quadres, murals o obres de l'artista per a veure el tipus de tècnica, dibuixos, formes, colors i materials que utilitza. Els analitzarem i comentarem entre tots per a després passar a treballar la seva tècnica.

En la segona part de la sessió, proporcionarem als alumnes una gran quantitat de material de tot tipus per a que siguen ells mateixos els qui identifiquen, entre tots, els més característics de l'artista que treballem i començar ja a pintar i imitar les seues obres. Penjarem en la pissarra una sèrie d'imatges de l'autor per a que els alumnes tinguen un model mentre pinten.

En la primera part de l'activitat "Treballem la tècnica de l'autor" que és la que ens ocupa, es tracta d'experimentar amb els diferents materials, suports i colors, per a, en la segona part, començar ja elaborar la nostra pròpia obra personal, seguint l'estil de l'artista i les tècniques que més els van agradar en la presa de contacte.

Hem de tenir en compte, en aquests tipus de activitats, el temps que ocupem en la preparació i recollida del material que utilitzem, per tal de planificar-les millors. 
Annex 2: EXEMPLE 2. ACTIVITATS DEL PROJECTE

\begin{tabular}{|c|c|}
\hline Títol activitat & EXPOSICIÓ DELS TREBALLS - A FER DE GUIES! \\
\hline Lloc & Instal·lacions del centre (corredors) \\
\hline Duració & 2 hores \\
\hline Materials & Treballs artístics dels xiquets i cinta adhesiva o blue-tack \\
\hline $\begin{array}{l}\text { Desenvolupament } \\
\text { de l'activitat }\end{array}$ & $\begin{array}{l}\text { Aprofitant tot el treball realitzat pels xiquets, demanarem permís al } \\
\text { Centre per tal de realitzar una exposició per les instal-lacions d'aquest. } \\
\text { Per tal que la tasca no siga tan costosa, la mestra encarregada haurà } \\
\text { disposat els espais (buidant-los de materials anteriors, acondicionant-los, } \\
\text { preparant el material que siga necessari...). així, quan els xiquets entren a } \\
\text { l'aula, no tindran tanta feina. } \\
\text { Els treballs seran penjats de les parets amb blue-tack o cinta adhesiva, de } \\
\text { manera que els xiquets puguen fer-ho per si mateixos. } \\
\text { La preparació de l'exposició anirà acompanyada d'una visita guiada. En } \\
\text { canvi, en aquesta ocasió els alumnes seran els guies i els visitants de } \\
\text { l'exposició, els xiquets d'alguna de les altres classes. } \\
\text { En principi, seria aconsellable que els visitants de l'exposició foren els } \\
\text { xiquets d' Infantil, concretament els de } 5 \text { anys ja que si el projecte } \\
\text { continuara l'any vinent, seria una manera de començar a connectar-los } \\
\text { amb aquesta forma de treball. Ara bé qualsevol classe pot ser } \\
\text { benvinguda. } \\
\text { A les } 17 h \text {, continuarem fent de guies però aquesta vegada, amb els pares. } \\
\text { els convidarem a que entren al centre i observen el treball realitzat. }\end{array}$ \\
\hline Observacions & \\
\hline
\end{tabular}




\section{Annex 3: QÜESTIONARI DE DETECCIÓ DE NECESSITATS EN EL PROFESSORAT}

$$
\text { CURS }
$$

SEXE:

Contesta les següents qüestions marcant amb una $\mathrm{X}$ la casella desitjada:

\begin{tabular}{|c|c|c|}
\hline & SI & NO \\
\hline 1.Treballar l'art en les escoles és important? & & \\
\hline 2. Creus que es treballa suficient? & & \\
\hline 3. Les hores que es dediquen a plàstica són suficients? & & \\
\hline 4. Creus que es trau el màxim possible? & & \\
\hline 5. L'art és complicat i no es pot treballar en l'aula? & & \\
\hline 6. Els alumnes mostren interès cap a l'assignatura de plàstica? & & \\
\hline 7. Treballar l'art fomenta la creativitat de l' alumnat en les escoles? & & \\
\hline 8. Consideres que treballar per projectes en educació fomenta la creativitat? & & \\
\hline $\begin{array}{l}\text { 9. Aprendre expressió artística és més que aprendre tècniques per a dibuixar i } \\
\text { pintar? }\end{array}$ & & \\
\hline 10. Els mestres tenen recursos per a treballar la plàstica dins l'aula? & & \\
\hline 11. Els mestres deuen incloure en els seus currículum l' art i la seva didàctica? & & \\
\hline 12. Els alumnes mostren interès cap a l'assignatura de plàstica? & & \\
\hline 13. Has treballat alguna vegada en aquest cicle l'art per projectes? & & \\
\hline $\begin{array}{l}\text { 14. L'experimentació de la plàstica fora de l'aula pot influenciar positivament en } \\
\text { el seu aprenentatge? }\end{array}$ & & \\
\hline $\begin{array}{l}\text { 15.Les visites als espais d' art poden modificar les meves idees sobre l'expressió } \\
\text { plàstica? }\end{array}$ & & \\
\hline 16. Coneixes els espais d'art que es troben a la ciutat? & & \\
\hline 17. Organitza el centre visites a aquests tipus d' espais? & & \\
\hline 18. Durant el primer cicle de Primària, has realitzat alguna d' aquestes visites? & & \\
\hline 19. Creus que fomenten I' aprenentatge de l'art? & & \\
\hline $\begin{array}{l}\text { 20. Creus que un major coneixement de l' art pot ajudar en la teua tasca com a } \\
\text { docent? }\end{array}$ & & \\
\hline
\end{tabular}




\section{Annex 4: PROTOCOL D'ACTUACIÓ PER A LA VISITA A UN ESPAI ARTÍSTIC}

(adaptació realitzada per a l'EACC)

\section{- QUÈ ÉS L'EACC?}

L'EACC és un centre per a la producció i admiració de l'art contemporani, que s'està consolidant com un punt actiu a nivell cultural $\mathrm{i}$ artístic a la ciutat de Castelló. Aquest reflecteix noves estratègies d'acció; revitalitza noves estratègies d'utilització de l'espai; involucra la ciutat convertint-la en un escenari real per a impulsar les pràctiques artístiques i culturals; estableix una xarxa de treball amb altres museus; estimula la participació dels visitants, promou la investigació i l'anàlisi; genera opinió i debat sobre l'art contemporani; posa en marxa projectes a la vegada que prepara exposicions i activitats i connecta les seues exposicions amb iniciatives artístiques públiques que tenen lloc en l'espai urbà, social i econòmic de la ciutat.

A més, té una concepció de l'espai per a les exposicions i del Museu mateix molt flexible, donant la possibilitat de desenvolupar un context que permeta desenvolupar noves formes d'entendre el futur.

\section{- L'EACC PER ALS MÉS MENUTS}

L'EACC és un espai que dona cabuda a tot tipus de públic; això implica tenir en compte als més menuts. Per tal d'aconseguir-ho, l'EACC posa a disposició dels centres una sèrie de vistes guiades adaptades a l'edat dels xiquets de manera que ells també puguen conèixer i participar d'aquest espai.

\section{- LOCALITZACIÓ}

L'EACC es troba al centre de Castelló, al costat del Conservatori i l'Escola Superior d'Art i Disseny, darrere de la plaça Borrull.

C/ Prim, s/n

$\mathrm{CP} / 12003$

Castelló 


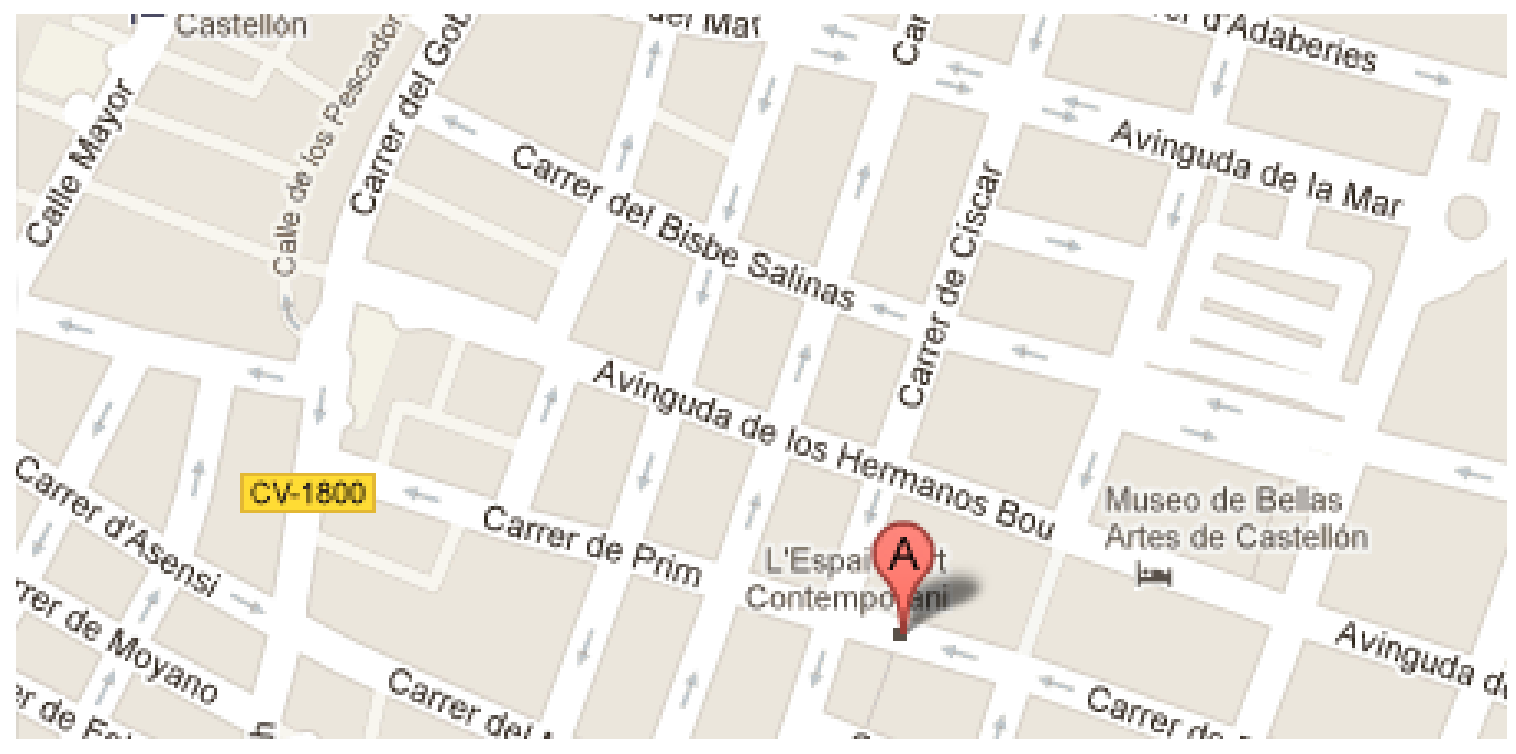

- COM ARRIBAR?

\section{En cas d'anar en tren:}

Des de l'estació de RENFE, Autobús línea 9: parada plaça Borrull.

En cas d'anar en cotxe o autobús:

Autopista A-7; Eixida Castelló Sud, direcció centre ciutat fins a plaça Fadrell.

\section{- HORARI}

Dimarts a diumenge de $10 \mathrm{~h}$ a $20 \mathrm{~h}$

Dilluns tancat

\section{- PREU}

Entrada gratuïta

- CONTACTE

Tel +34 964723540

Fax +34964 260771

eacc@eacc.es

\section{- COM ORGANITZAR UNA VISITA?}

\section{Pel que fa a l'EACC...}

Tots els divendres, I'EACC posa a disposició del públic un servei de visites guiades de les exposicions. Les visites comencen a les $19 \mathrm{~h}$ i tenen aproximadament una hora de duració. 
També es poden concertar visites per a grups d'adults i escolars durant la setmana. (Mínim 10 persones). En el nostre cas, aquesta seria l'opció a triar ja que l'activitat hauria de realitzar-se dins l'horari escolar.

Per a posar-nos en contacte, hauríem de cridar al telèfon que apareix a l'apartat anterior (964 7235 40) i acordar el dia de la visita amb Juan Francisco Fandos, responsable de les activitats de l'Espai.

\section{Pel que fa al centre...}

Una vegada sabem que és possible la realització d'una visita a l'EACC, haurem de demanar permís al centre per tal de rebre el seu consentiment. Haurem de presentar un document on s' explique què és I'EACC, el tipus d'activitat a realitzar i la intenció educativa d'aquesta (dins del projecte globalitzat). Aquesta proposta ha de ser aprovada per l'organisme escolar adient.

Amb el permís del centre, a continuació és necessari convocar una reunió informativa per als pares de manera que ells també tinguen coneixement del que es vol fer i decidisquen si els seus fills volen participar.

Aleshores, es podrà concertar la cita definitiva amb l'EACC per tal de realitzar la visita adient.

En el moment de realitzar la visita, una setmana abans es prepararan les autoritzacions (que els xiquets hauran de portar signades) per tal de saber el nombre de xiquets que assistirà a la reunió. 
